\title{
Male Partner Involvement In The Utilization Of Antenatal Care Services In Kidera, Buyende District, Uganda: Cross Sectional Mixed Methods Study
}

Priscilla Alupo

Busitema Univesity

Esther Ruth Atim

Busitema University

Henry Kaggwa

Busitema University

Calorine Mudondo

Busitema University

Cliveland Ogallo

Busitema University

Jesse Ogwang

Busitema University

Benon Wanume

Busitema University

Rebecca Nekaka

Busitema University

Julius Nteziyaremye ( $\square$ jntezi@gmail.com )

Busitema University https://orcid.org/0000-0002-6286-2867

\section{Research}

Keywords: Male involvement, Antenatal care, Buyende, Uganda

Posted Date: July 1st, 2020

DOI: https://doi.org/10.21203/rs.3.rs-38709/v1

License: (c) (i) This work is licensed under a Creative Commons Attribution 4.0 International License.

Read Full License 


\section{Abstract}

\section{Background:}

Antenatal care, one of the pillars of safe motherhood, is a proven a concept aimed at reducing maternal and neonatal morbidity and mortality. It is a largely a health preventive and promotive activity. In order to foster its utilization and the desired benefits, the males who are largely key decision makers especially in patriarchal societies have to be involved. This concept of male involvement (MI) is essential in curtailing the gender inequality and improves the family livelihood. Although different strategies have been employed to woe males into ANC clinics, their involvement is largely lacking in Uganda. This study reports level of males' involvement, their knowledge and attitudes of ANC and influencing factors .

Methods: This was a cross sectional community descriptive study that employed quantitative and qualitative methods. Our qualitative data study was based on the phenomenological design and rooted into the Grounded theory. For quantitative study, 135 adult males were recruited and collected data analyzed using SPSS software (version 24) while for qualitative data collection, Focus Group Discussions(FGDs) were held for 60 males and each transcript was analyzed by two researchers using NVIVO software version 12.Coding was done and themes developed.

Results: Male involvement as assessed based on different activities was between $51.1 \%$ and 85.2 \%.Although $77.8 \%$ had ever accompanied their partner for ANC, only $9.6 \%$ did so on at least 4 occasions and $88.9 \%$ never received any supplementary service during the visit. Significantly males were generally knowledgeable and had positive attitude towards ANC. Also $65.4 \%$ reported their partner felt comfortable once accompanied.

However during FGDs, males described ANC as a room for checking pregnant women, time wasting and unpleasant for the males with no privacy and rude staff. They were further wary of being tested as a couple for HIV. Despite challenges, ANC couple attendance was credited with potential of fostering unity.

Conclusions: Male involvement is improving in Uganda but more needs to be done in educating men about their importance in ANC. Couple friendly infrastructure that ensures privacy, staff training that ensures customer care tailored towards being more sensitive and responsive to couples' may improve MI.

\section{Background}

Male involvement (MI) is an all-encompassing term, referring to the various ways in which men relate to reproductive health problems and programs, reproductive rights and reproductive behavior. It is considered to be an important cornerstone for improving maternal health globally. It calls for the need to change men's attitude and behavior towards women's health, make them more supportive of women to and during use of health care services and sharing childbearing activities. Furthermore it emphasizes that men's understanding of their responsibility for their sexual and reproductive behavior as well as their 
social and family role is essential in curtailing the gender inequality and improve the family livelihood[14]

The recognition of the need to involve men in Maternal and Child Health(MCH) programmes has been realized since the mid-1990 s, given the important role men have as partners/ husbands, fathers and community members and as a way of promoting egalitarian decisions about reproductive and maternal health and more so in patriarchal societies[5].

Antenatal care is one of the pillars of safe motherhood: a concept aimed at reducing maternal and neonatal morbidity and mortality and to improve the maternal and neonatal health through preventive and promotive activities as well as by addressing avoidable factors that cause death during pregnancy, childbirth and postpartum period[6]. Antenatal care in Uganda and beyond has proven to reduce mortality [7-10] and is considered as a public health necessity[11].Moreover male involvement is seen to improve attendance and intended results of Antenatal care[12, 13]

In 2015 during the $70^{\mathrm{TH}}$ United Nations General Assembly, the Millennium Development Goals (MDG) were replaced by the more robust, Sustainable Development Goals (SDG). SDG 3.1 specifically focuses on reduction of global maternal mortality ratio (MMR) to less than 70 per 100000 live births by 2030, and to have no country with MMR above 140[14]. Yet in 2015, about 303000 women died of maternal causes and maternal mortality emerged as the second leading cause of death only bettered by Human immune virus among women aged 15-49yrs. Whereas globally the lifetime risk of dying due to maternal death is 1 in 180,Africa's high MMR of 540 per 100000 live births coupled with high fertility levels translate into a lifetime risk of dying from maternal causes of 1 in 37[15, 16].Not surprising therefore, more than $99 \%$ of maternal deaths occur in the developing World with almost half occurring in sub-Saharan Africa(SSA)[17, 18].

Each year, almost a third of maternal deaths worldwide are directly related to inadequate care during pregnancy .Empowering women in and increasing male involvement in sexual and reproductive Health are both seen as significant strategies to reduce preventable maternal morbidity and mortality worldwide[9, 19-21]. MI does not only improve maternal outcomes but also reduces perinatal mortality and morbidity, improves successful implementation of prevention of mother to child Human Immune deficiency transmission, improves uptake of family planning services, increased access to postnatal and antenatal care, enhancement of healthy maternal practices such as good nutrition, improved maternal mental health, increased likelihood of contraceptive usage and allayment of stress, pain and anxiety during delivery and postpartum depression[12, 13, 20, 22-26]. In fact Male involvement during pregnancy and pueperium appeared to have greater benefits than male involvement during delivery in developing countries compared to the developed countries[12].Among the black women, paternal involvement has the capacity to prevent excess mortality by about $65-75 \%[13]$

Studies in different parts of the World and even same country show heterogeneity regarding the level of $\mathrm{MI}$ its facilitators and barriers. In a study to assess determinants of Male partner attendance of skilled 
antenatal care in peri-urban Gulu district, Northern Uganda, $65.4 \%$ of males had attended at least one skilled antenatal care visit with factors such as knowledge of 3 or more ANC services, obtaining health information from facility health workers and if spouse had skilled attendance at last childbirth were seen as facilitators of male involvement whereas male partners intending their spouse to carry another pregnancy and living more than $5 \mathrm{Km}$ from a health facility were barriers to male involvement[27].A study in central Uganda showed an appallingly low level of male involvement with $6 \%$ of male consistently involved while $94 \%$ were inconsistently involved[28]. A study in Ghana also found low levels of ANC involvement with only $35 \%$ of males accompanying their wives .Male involvement in antenatal care and delivery was influenced by sociodemographic (partner's education, type of marriage, living arrangements, and number of children) and enabling/disenabling (distance to health facility, attitude of health workers, prohibitive cultural norms, unfavorable health policies, and gender roles) factors[29], unfriendly antenatal care environment with lack of space to accommodate the couple, longer waiting tine at ANC clinics due to administrative bureaucracy, charging of unofficial ANC extra fees by health workers, use of critical harsh language [22, 30-32] and in Nepal it was revealed that low education status, high income status, and age above 25 years positively affected male involvement[33]

We therefore set out to study level of male's involvement, their knowledge and attitudes of ANC services in Kidera sub-county, Eastern Uganda.

\section{Theoretical Framework}

In a bid to understand the subject of male involvement in ANC, we based our qualitative data study on the phenomenological design.

Grounded theory formed the basis of our study in which we presupposed that behaviors and social relationships were key to influencing men's involvement in Antenatal care (ANC).

The level / extent by which men feel involved coupled with their attitude and knowledge of ANC would influence their involvement.

\section{Materials And Methods}

Materials and methods

\section{Study setting.}

The study was conducted in Kidera Sub-county of Buyende district. Buyende district located in Eastern Uganda. It covers an area of $18,880.7 \mathrm{~km}^{2}$, a population of 158,615 males and 164,452 females giving a total of 323,067 with males to female ratio of $96: 100$ [34] and density $141 / \mathrm{km}^{2}$. Buyende district has 5 sub counties namely Bugaya, Buyende, Kagulu, Kidera and Nkondo. Kidera was chosen by random sampling. Kidera has six parishes namely Bukungu, Buyanja, Kasiira, Kidera, Miseru and Ntaala and has a population of males 42,100 and females 42,300(Uganda Bureau of Statistics 2020). 
- It also happens that Kidera Sub County is the only one with Comprehensive Emergency Obstetric care (CEMOC) services providing health facility.

\section{Study Design, Participants And Sampling Procedure}

We did a community-based descriptive cross-sectional study using both quantitative and qualitative approaches between July and June 2019.Study participants were males of at least 18 years of age who had had a partner or wife currently gravid or had been gravid and attending ANC in the past 1 year prior to the study period and lived in Kidera sub county. Sample size was estimated using the modified Kish Leslie (1965) survey sampling formula with a 95\% confidence interval (Z score on the normal distribution curve corresponding to $95 \%$ level of confidence $=1.96$ ), a precision of $5 \%[35]$, and an estimated proportion of male partners attending ANC of $6 \%[28]$.

Therefore sample size, $\mathrm{N}=(1.96)^{2} \times 0.06 \times 0.94 /(0.05)^{2}=0.217 / 0.0025=87$ participants. We however increased our sample size by $50 \%$ to increase power. Therefore we interviewed 135 participants

\section{Number of services received at ANC.}

Whereas most women have the opportunity to interact with the health care system during ANC, most men only do so once ill. Involvement in Sexual and Reproductive health (SRH) during ANC has been seen as a 'doorway' into the health care system. We asked these males about a service they had ever received from a health facility once they accompanied their partner.

\section{Data Management And Analysis}

For quantitative study method, we used purposive sampling to selected males who had had a partner or wife currently gravid or had been gravid and attending ANC in the past 1 year prior to the study period and lived in Kidera Sub County. This was done with the help of the Village Health Team (VHT). Data was collected using face to face interviewer administered pretested questionnaires. This data included sociodemographics, knowledge and attitude towards ANC, activities that are indicative of male involvement in their partner's ANC services and services they had ever received at the Antenatal care clinics. A 14-point knowledge scale was used to measure the respondents' knowledge of ANC. A correct response attracted a score of 1 point while a wrong knowledge one, zero. A score of $\leq 5$ points was considered poor while scores of 6-10 and 11-14 points were considered moderate and good knowledge, respectively. We used three parameters to measure the men's attitude towards ANC. These included: would use ANC, necessity for male partner involvement and finally partner's comfort when escorted to the ANC clinic. (Supplementary data)

For the qualitative study phenomenological study design was used. Researchers who had been trained in qualitative data collection and had not interacted with this community before the research collected data with the aid of Focus Group Discussions (FGDs). The researchers used Village Health team members to 
help them organize the participants. They introduced themselves, purpose of the study and sought informed written consent (in either a signature or thumb print mark on the informed consent form) from the participants. FGD were grouped into those for men below 35 years (youth) and those above 35 yrs of age. In order to freely achieve our target, we visited the recreational facilities such as football grounds for the youth and social gathering places such as bars for those older. Each FGD comprised of 5-10 men and lasted 1-1.5hours. Three were held at the different community bars as we targeted fathers older than 35 years of age and the other 4 FGDs were held at the football pitches and cinemas. No initial sample size was set for the study. In total we had 60 participants out of the 73 that were approached. The 13 declined on the basis of not having time. Unique numbers were then assigned to each participant to ensure anonymity. In all circumstances the VHT member introduced us and a village meeting place nearby was used. We used interview guide questions that were developed in English but translated also in Lusoga (local language) and were pretested on the three participants before data collection began. We stopped after reaching a point of saturation. Each focus group discussion had 2 researchers. Interviews were largely carried out in Lusoga, audio recorded and field notes written in a hand book. They were later transcribed and translated into English verbatim. Open coding, in which process concepts and key phrases were identified and highlighted and moved into themes.

After completion of quantitative data collection, each questionnaire was assigned a number in form of codes so that the questionnaire could be rechecked if the need arose. The data collected from the 135 respondents were entered into Microsoft excel processed and analyzed using SPSS software (version 24). Simple proportions were used to describe categorical data at univariate level and presented in frequency and percentage distributions. After each Focus Group discussion, each transcript was analyzed by two researchers working independently to reduce bias using NVIVO software version 12.Coding was done manually based on the key words and phrases developed from the data. The codes were then grouped together into higher order headings. Accordingly on a higher logical level of abstractions codes, subcategories, categories and themes were formed. The themes were categorized according to the ANC as a small room for only midwife and pregnant woman, ANC as a couple serving centre, male's role as providers, couple ANC attendance as determinant of family direction and ANC as unpleasant place.

\section{Ethical considerations}

Ethical clearance was obtained from the department of Community Education Research and Services (COBERS) and from by Mbale Regional

Referral Hospital Institutional Review Board (MRRHIRB). Informed written consent was obtained from each participant .For purposes of

Confidentiality, interviews were held in privacy and codes rather than names of participants.

\section{Results}


Table 1

Sociodemographic characteristics of the 135 male participants

\begin{tabular}{|c|c|c|}
\hline VARIABLE & Frequency $(\mathrm{N}=135)$ & Percentage (\%) \\
\hline \multicolumn{3}{|l|}{ Age } \\
\hline 19 to 24 years & 12 & 8.89 \\
\hline 25 to 29 years & 25 & 18.5 \\
\hline 30 to 34 years & 29 & 21.5 \\
\hline$>=35$ years & 69 & 51.1 \\
\hline \multicolumn{3}{|l|}{ Religion } \\
\hline Christians & 97 & 71.9 \\
\hline Moslem & 35 & 25.9 \\
\hline Others & 3 & 2.2 \\
\hline \multicolumn{3}{|l|}{ Marital status } \\
\hline Cohabiting & 11 & 8.2 \\
\hline Married & 122 & 90.4 \\
\hline divorced & 2 & 1.5 \\
\hline \multicolumn{3}{|l|}{ Level Of Education } \\
\hline No formal education/ & 7 & 5.2 \\
\hline Primary & 66 & 48.9 \\
\hline Secondary & 58 & 43 \\
\hline Tertiary/college & 4 & 3.0 \\
\hline \multicolumn{3}{|l|}{ Occupation } \\
\hline Informal & 7 & 5.3 \\
\hline Civil servant & 3 & 2.2 \\
\hline Peasant & 77 & 57.0 \\
\hline Others & 48 & 35.56 \\
\hline \multicolumn{3}{|l|}{ Number of children } \\
\hline ( $0-5$ children) & 75 & 55.56 \\
\hline (6-10 children) & 40 & 29.63 \\
\hline (11-15 children) & 48 & 9.63 \\
\hline
\end{tabular}




\begin{tabular}{|lll|}
\hline VARIABLE & Frequency $(\mathbf{N}=135)$ & Percentage (\%) \\
\hline Above 15 children) & 77 & 5.19 \\
\hline Living with partner & & \\
Yes & $133(98.5)$ & \\
No & $2(1.5)$ & \\
\hline Services ever received & \\
\hline HIV testing & $132(97.9)$ & \\
\hline Only 1 supplementary service & $10(7.4)$ & \\
\hline More than 1 supplementary service & $5(3.7)$ & \\
\hline No service received at all & $120(88.9)$ & \\
\hline Average number of ANC & $13(9.6)$ \\
\hline At least 4 & $31(23)$ \\
\hline 3 times & $68(50.4)$ \\
\hline $1-2$ times & $23(17)$ \\
\hline none &
\end{tabular}


Table 2

Knowledge and attitudes of males towards Antenatal care involvement. Knowledge levels scores

\begin{tabular}{|lll|}
\hline Sufficient knowledge $(11-14)$ & 12 & 8.9 \\
\hline Moderate knowledge $(6-10)$ & 83 & 61.5 \\
\hline No knowledge $(0-5)$ & 40 & 29.6 \\
\hline Would use ANC & 129 & 95.56 \\
\hline Agree & 2 & 1.48 \\
\hline Disagree & 4 & 2.96 \\
Neutral & & \\
\hline Find it necessary for men to be involved & 129 & 95.56 \\
\hline Agree & 4 & 2.96 \\
\hline Disagree & $2(1.5)$ & \\
\hline Neutral & & \\
\hline Partner feels comfortable when accompanied & & \\
\hline Agree & $126(93.3)$ & \\
\hline Disagree & $5(3.7)$ & \\
\hline Neutral & $4(3.0)$ \\
\hline
\end{tabular}


Table 3

VARIABLES THAT DEFINE MALE INVOLVEMENT IN ANTENATAL CARE

\begin{tabular}{|lll|}
\hline VARIABLE OF MALE INVOLVEMENT & YES (\%) & No (\%) \\
\hline I accompanied her to ANC clinic & $105(77.8)$ & $30(22.2)$ \\
\hline I provided her with transport to attend ANC & $81(62.2)$ & $54(37.8)$ \\
\hline I provided her with food and money to feed her during pregnancy & $107(79.3)$ & $28(10.7)$ \\
\hline $\begin{array}{l}\text { I brought for her the necessary requirements in regards to pregnancy for } \\
\text { example the baby's clothes and delivery(mama)kit }\end{array}$ & $115(85.2)$ & $20(14.8)$ \\
$\begin{array}{l}\text { I escorted her to the ANC clinic and took part in the various activities at the } \\
\text { ANC clinic }\end{array}$ & $69(51.1)$ & $66(48.9)$ \\
\hline $\begin{array}{l}\text { Average number of ANC visits } \\
\text { At least } 4 \text { times }\end{array}$ & $13(9.6)$ & \\
\hline 3 times & $31(23)$ & \\
\hline 1-2 times & $68(50.4)$ \\
\hline Never attended ANC & $23(17)$ \\
\hline
\end{tabular}


Table 4

Sociodemographic characteristics of participants

in the focus group discussions

\begin{tabular}{|ll|}
\hline Variable & Number, $\mathbf{n}(\%)$ \\
\hline Age (yrs) & \\
\hline $18-24$ & $5(8.3)$ \\
\hline $25-29$ & $21(35)$ \\
\hline $30-34$ & $18(30)$ \\
\hline $35-39$ & $10(16.7)$ \\
\hline$>40$ & $6(10)$ \\
\hline Occupation & \\
\hline Fishermen & $5(8.3)$ \\
\hline Peasant & $35(58.3)$ \\
\hline Bodaboda cyclist & $15(33.3)$ \\
\hline Formal & $5(8.3)$ \\
\hline Level of education & \\
\hline No formal/primary education & $46(76.7)$ \\
\hline Secondary & $12(20)$ \\
\hline Others & $2(3.3)$ \\
\hline Religion & \\
\hline Christians & $45(75)$ \\
\hline Muslims & $14(23.3)$ \\
\hline Others & $01(1.7)$ \\
\hline Marital status & $56(93.3)$ \\
\hline Married /cohabiting & \\
\hline Single/divorced & \\
\hline
\end{tabular}

\section{Sociodemographic Characteristics}

The study involved 135 males and all were above 18 years of age and thus considered as adults. Slightly above half of the participants were equal to or above 35years, $51.1 \%(69 / 135)$ and only $8.9 \%(12 / 135)$ were young men between 19 to 24 years. Majority of the participants, $71.9 \%$ (97/135) were Christians 
while Moslems were $25.9 \%$ (35/135). Majority, 98.5\% (133/135) were currently staying with partners as wives in a heterogeneous sexual relationship. Of these, $94.4 \%(122 / 135)$ were officially married. Two men were divorced (1.5\%). Most men had had some formal education $94.8 \%(128 / 135)$ with close to $45.9 \%($ $62 / 135)$ attaining at least secondary school education and only $5.2 \%(7 / 135)$ had no formal education.

Regarding the number of children, slightly above half of the respondents, $75 / 135(55.6 \%)$ had $0-5$ children while about $5.2 \%(77 / 135)$ had 15 or more

children. Furthermore, $99.3 \%(134 / 135)$ were engaged in some form of employment with informal sector accounting for $97.1 \%(131 / 135)$ and only

$2.2 \%(3 / 135)$ were formally employed. Majority $98.5 \%$ (133/135) were staying with their partners while only $1.5 \%(2 / 135)$ were not staying with the

partner during the pregnancy. (Table 1)

We assessed attitude of the respondents towards ANC and there was over $90 \%$ score for each parameter with $95.6 \%(129 / 135)$ emphasizing that

they would agree to use ANC, $95.6 \%(129 / 135)$ agreeing to finding it necessary for men to get involved in ANC and $93.3 \%(126 / 135)$ agreeing to

partner's comfort. Moreover men's knowledge of ANC was relatively good with the majority, $70.4 \%$ $(95 / 135)$ expressing moderate to sufficient

knowledge (scores 6-14). Significantly only 8.9\% (12/135) had sufficient knowledge on ANC. Regarding the knowledge about ANC

(recommended visits, services offered, benefits to both mother and unborn child and the risks associated with absconding), they were

relatively knowledgeable with the majority $61.5 \%$ expressing moderate knowledge and $8.9 \%$ sufficient.( Table 2)

Among the participants in the focus group discussions, majority were youth and young men, with $65 \%$ accounted for by 25-34 year olds. Christians

constituted the majority at $75 \%$ and most were largely staying with a partner at $93.3 \%$.Regarding employment status majority were in the informal

Sector, at $91.7 \%$ while still $76.7 \%$ had attained either no formal education of had attended primary level (Table 4)

\section{Male Involvement}


Several areas were assessed to determine the level of male partner involvement in the utilization of ANC services (Table 3).

Significantly, no parameter measured was below 50\%.Majority of males, $85.2 \%$ (115/135) self reported participating by making sure that the necessary requirements in regards to pregnancy are available. Moreover while $77.8 \%$ reported having accompanied a partner to the ANC clinic while $22.2 \%$ did not. Among the 20 men that never accompanied their partners, 30\% (6/20) did not know about ANC while 25\% $(5 / 20)$ did not do so because they were not staying together. The rest did not accompany partners because of being busy, 45\%(11/20).(Fig. 1)

Also, whereas the majority of males, $83 \%$ ever attended ANC only $50.4 \%$ attended $1-2$ visits and as the contacts increased thereafter the percentage attending declined. Noteworthy is that only $9.6 \%(13 / 135)$ ever attended at least 4 ANC clinics. Moreover only $51.1 \%$ took part in the various activities at the clinic. (Table 3)

\section{Number of services received at ANC.}

The services that were provided included taking their Blood pressure, body weight, nutritional status assessment (by measuring Mid Upper arm circumference (MUAC)) and Human Immune Virus (HIV) testing. HIV serology testing was the major service offered to men, $97.9 \%(132 / 135)$.Significantly, $88.9 \%$ (120/135) never had any supplementary services provided during ANC. However, 15/135 males (1.1\%) received at least a supplementary service with $3.7 \%$ (5/135) receiving more than one service.(Fig. 2)

\section{Qualitative data results.}

This was done through a phenomenological approach with inductive thinking. Focus group discussions were used to explore what the males thought of ANC and the services provided and to understand the level of their participation. The participants were asked five questions which were answered as follows.

\section{Theme1: ANC as a small room for only midwife and pregnant woman?}

Whereas they were mixed answers to what men thought ANC was, majority submitted that ANC was a small room where the midwife enters with the pregnant woman and the latter is checked.

15 males described it as a small room where the midwife takes your wife and you are told to wait from outside.

"During ANC your wife is taken into a small room and the midwives tell you to wait outside," said a 26 year old participant

However 10 males described it as a room where the midwife checks the status of the baby and the mother. 
"ANC is a place where you take your wife so that the midwife can check on the status of the baby and the mother." said 25 year old respondent

\section{Theme 2: Anc As A Couple Serving Centre}

With regards to male involvement in the ANC clinics, respondents reported that pregnant women and their spouses who were not sure of their HIV status were afraid of going together for ANC services. The respondents revealed that one of the basic services provided at the clinic during the first ANC visit was HIV counseling and testing. According to our respondents, the majority of men did not want to take HIV testing. To them, testing for HIV was soliciting problems.

15 participants said, they were afraid of testing for HIV status with their female partners.

However others appreciated it since they could get to know together and get necessary treatment.

"You are asked as a couple to test your HIV status and in case one of you is positive you are given ARVs (antiretroviral drugs)" They also reported,

During ANC you are given health education as a couple and thereafter the wife is given some tablets to take to ensure that the baby grows well.

\section{Theme 3: Males' Role As Providers}

During the discussions, males expressed several ways in which they are involved.

"We are involved," said 27 years old.

"Involvement! ...paused.. What do you call male involvement, all men are involved in one way or the other", replied 35 year

"So we are involved", said 29 year old

"I ensure that the mother sleeps in a mosquito net," said a 57 year old respondent

"The man should buy clothes and delivery kit," said 42 year old

"A man should escort the mother for ANC or provide transport in case you are busy, "said a 35 year old.

"Provide a balanced diet for the mother to make sure she is healthy', said a 27 year old

Theme 4: Couple ANC attendance as determinant of family direction

Majority agreed that attendance of ANC as a couple may help foster unity and build stronger family ties although others expressed fear of the end of marriage in case during HIV testing, one turned out 
seropositive.

"As a couple it creates unity and my wife feels really loved when I escort her." All said,

ANC "It is a good thing because it helps us as a couple knows the status of the baby hence prepare accordingly."

And 12 said, "In case I test positive that could be the end of our marriage."

It is a risky idea because of the mandatory HIV testing; we could part ways in case I turned out positive.

Theme 5: ANC as unpleasant place.

Most males decried the environment and mood at the facilities.

15 of the responses were "The mid wives are so rude, you can't even think of going for another visit." "You sit from $8 a m$ till $3 \mathrm{pm}$ and sometimes even $5 \mathrm{pm}$ "

17 of the men said, "The men are never attended to, it's only the women, we stay idle the entire time."

"The midwives are so rude, you can't even think of going for another visit." said 36 year old participant

"The men are never attended to, it's only the women, we stay idle the entire time", 29 old said

We are fishermen; we work during night and sell off our catch in during day so our work schedule cannot allow us to take part consistently.

"My wife is disabled and whenever I walk with her in public I am laughed at", said a 27 year old

\section{Discussion}

This study shows that male partner involvement in ANC is high with parameters used for assessment scoring between $51.1 \%$ ( I escorted her to the ANC clinic and took part in the various activities at the ANC clinic) to as high as $85.2 \%$ (I brought for her the necessary requirements in regards to pregnancy for example the baby's clothes and delivery kit (Mama Kit)). These findings are similar to a study in Tanzania that showed a high proportion of males getting involved in different antenatal activities[36] and in Ghana by Maxwell et al who revealed that $67.2 \%$ scored high for male involvement while only $32.8 \%$ scored low for male involvement[37] and 39.3\% in a study in Nepal ever accompanied their partners[33] while Atuahene et al revealed only $8.4 \%$ of the surveyed males in Ghana had ever accompanied their partner for Antenatal[38].Like in Mbeya, [39] men in our study largely provided transport to facilitate ANC attendance $(86.8 \%$ versus $81 \%)$

In our study although $77.8 \%(105 / 135)$ of the males had ever accompanied their partners for antenatal, only $9.6 \%$ had done so on 4 or more ANC contacts. This finding contrasted the one by Jennings et al and Atuahene et in which only $49.7 \%$ and $8.4 \%$ of males had done so in Uganda and Ghana respectively [38, 
40].However Jennings et al study analyzed Demographic and Health Survey data 2010-2011 from different countries while the difference in Ghana may be that it is a Western African country where culture may be different that of our study population. Moreover the Ghananian community was largely a fishing community. However the findings showed $83 \%$ accompanying a partner to at least to one ANC contact which is in agreement with a study in neighbouring Tanzania in which 63\%[36] did so and in Northern Uganda where at least 65.4\%[27] attended at least one visit. Moreover the study agreed with findings in Ghana by Atuahene et al in that only $8.5 \%$ of the $8.4 \%$ of those males that accompanied partners for ANC did so 4 or more times compared to our $9.6 \%$ [38]. However more men are involved in buying the requirements for antenatal and food for better nutrition of the expectant mother. This may be explained by the fact that while many men may consider it their responsibility to provide and support their wives during pregnancy, they may not see accompanying them to ANC as part of their obligation. Therefore in African setting male involvement should go beyond just escorting one partner to the ANC clinics but include aspects like support at home during pregnancy that will enhance the good health outcome of the mother and baby. This was echoed during the FGDs in which males agreed that they all support their partner in one way or the other during pregnancy. This study, however, corroborated with a study conducted in the central region of Ghana where it was reported that although men are generally involved in ANC activities at the household and community level, they were not directly involved in activities such as accompanying their partners to the ANC clinics. The authors concluded that in order to understand well the subject of $\mathrm{MI}$, the matriarchal and patriarchal nature of our societies together with religious differences ,educational and generational demarcations must be taken into consideration[41]

In our study only $9.6 \%$ attended at least 4 contacts. In a study in Central Uganda, $94 \%$ of males did not consistently take part in ANC while only $6 \%$ did[28].The three top reason the males gave for their inconsistence were being busy(27.4\%),not being their responsibility $(19.7 \%)$ and long waiting times at the facility $(14.7 \%)$ [28].Like in this study, the single most reason the males gave for having never attended ANC was being busy at $30 \%$ followed by not knowing about ANC at $25 \%$. During the FGD, men reduced ANC to a small room where the midwife goes to check your wife and you are told to wait from outside in addition to the environment being an unpleasant place in which midwives were considered rude, characterized by long waiting hours while one was idle and not being attended to and insensitive to men with disabled partners. These findings are echoed in a studies in Ethiopia[42], Western Kenya by Ongolly et al, Tanzania by Peneza et al[43], a Cochrane review by Ditekemena et al[32, 44] and in Eastern Uganda by Byamugisha et al[31] and in India[45]. The lack of involvement in the facility activities may be evidenced by the fact that $88.9 \%$ had never received a service other than the mandatory HIV testing. HIV testing during ANC is mandatory in Uganda at the first interface with gravid mother[46] In a study in New Papua Guinea the involvement of men in sexual and reproductive health services and support of their wives was shown to be hampered by inappropriate services [47] yet studies have shown that such services are an incentive to MI[48]. Furthermore this could be caused by beliefs that ANC is a female's place as revealed in this study during FGD and supported by findings in Moshi, Tanzania[49] and in South Africa[50].The issue of men complaining about long waiting hours that are caused by the burdensome administrative procedures-a deterrent especially for the employed male partners is in tandem with 
findings elsewhere[22, 48, 50].In a South African study males proposed use of weekends and early morning hours as the better times for ANC[48]. Research has proven a correlation between the average number of visits attended per child and the occupation of the male partner as evidenced by the fact that more peasants showed up compared to the business men who said they are always busy[51] and others claimed that the kind of work they engage in can only allow them to be free during night when it is unfavorable to attend ANC[52]

Men acknowledged that attending ANC together may determine family direction. Majority, $67.4 \%$ of the men strongly agreed that their partners felt very comfortable and loved whenever they escorted them to the clinic and this prompted them to further engage in the practice. This revelation is confirmed by a in Northern Uganda in which $96 \%$ of the males thought attending spousal ANC was beneficial[27] while in South Africa $92 \%$ of the women expressed willingness to have their partners attend ANC with them[48].During the FGD, males appreciated that ANC is a couple service centre and they appreciated services extended such as HIV testing, care services and treatment services This finding was similar to findings of other studies in East Africa [31, 49]. However studies elsewhere have indicated that women are uncomfortable with their male partners accompanying them as ANC clinics are considered female places and males' presence limits free expression and honesty[42]

Whereas others regarded it as a unifying factor, others reasoned that the fact of HIV testing would be divisive if one turned positive. Many men expressed fear of disclosing their HIV status to their spouses as this poses a risk of family break-up. Similar findings were echoed elsewhere in Uganda[27] and Tanzania $[39,49]$.

Males were generally had good attitude towards ANC as $95.6 \%$ agreed not only to use the service but also agreed that it was important to involve males. This is in agreement with a study in India where $96 \%$ of male respondents agreed that ANC was valuable[45] that they would the service utilize ANC. Moreover males scored well on knowledge. The majority knew that ANC was very important for the pregnant woman, as it ensures the well-being of the mother and the child. This finding was similar to one found by Yargawa et al.[12]

In terms of medication during pregnancy, the respondent's knowledge was poor. Most men didn't know that pregnant women receive Tetanus vaccine during pregnancy. Knowledge of services received at the ANC was equally good. Much as a study in Kenya revealed that most men were less knowledgeable about HIV prevention in regards to ANC(Katz et al., 2009), this study showed that high percentage of the men $96.7 \%$ knew that HIV testing was important for the health of the mother and the unborn baby and an unborn baby can be prevented from getting HIV from its mother if its mother is HIV positive. This finding supports the evidence that increasing male partner's knowledge of safe motherhood is positively associated with attendance of ANC

\section{Recommendations.}


In order to promote male involvement in ANC and to address the barriers to their participation, the following strategies were recommended:

An active role of educating men on the importance of their involvement in ANC by all stakeholders needs to be undertaken.

The need for the midwives, physicians and other stakeholders maternal, neonatal and child health sector should be proactive in advocating for infrastructure and human resource investments that are accommodative of men, disabled clients and use of non-judgmental, client-friendly language should be emphasized since men are key shareholders in women's and children's health. On the other hand, the ministry of health should invest in better infrastructure-with future designs of health facilities could be made more couple-friendly, that guarantees all clients their privacy at the clinic during service delivery and as they wait for their services. Also, there will be the need for better planning and the institutionalisation of and sticking to booking/ appointment regime and instituting a functional referral system - currently absent in most public health facilities in Uganda - in a bid to reduce queues and long waiting times before care is received. Lastly, the government should come up with policies that are all-inclusive and involve men as key stakeholders sexual and reproductive health $(\mathrm{SRH})$, introduce male tailored services to reduce on male redundancy during ANC and consider extending ANC services to weekends.

\section{Conclusion}

From this study, males are generally involved in ANC although inconsistently. They have moderate knowledge and a good attitude towards ANC however their consistent involvement in ANC is still low as evidenced by low $4+$ ANC attendances. The major barriers cited are infrastructural challenges, poor attitude and disrespectful language directed towards them by health workers, longer waiting time and the limited service package for men that only emphasizes the mandatory HIV testing for couples. Heavy investment into infrastructure, human resources (in terms of numbers and improved conduct) and broadening the service package for men (such as including Random blood sugar testing, nutritional assessment et cetera) will be handy in improving male involvement.

\section{Declarations}

\section{Competing interest:}

The authors declare that there is no conflict of interest.

\section{Ethics approval and consent to participate:}

The ethical clearance letter was obtained Busitema University Higher degrees committee and administrative clearance was obtained from Buyende district leadership. Finally, written consent informed 
was requested from each participant. The participants were informed about the purpose. There were no potential risks except for the time spent during the FGDs.

\section{Consent for publication:}

Not applicable

\section{Availability of Data and Materials:}

This is available from the corresponding author,jntezi@gmail.com upon reasonable request.

\section{Funding:}

Directorate of Graduate Studies, Research and Innovations, Busitema University funded the manuscript writing.

\section{Authors' contributions}

$A P, A E R, K H, M C, O C, O J$,NJ and WB conceptualized the idea

\section{Acknowledgements}

; The authors extend their gratitude to the Department of Community and Public Health, Faculty of Health Sciences, Busitema University, Community Based Education and Research Services (COBERS) coordinator and Directorate of Graduate Studies, Research and Innovations ,Busitema University, Buyende district health workers and respondents who participated on this study.

\section{Abbreviations}

ANC-Antenatal care, COBERS-Community Education Research and Services, FGD-Focus Group discussion, HIV-Human Immune Virus, $\mathrm{MCH}$ -

Maternal and Child Health, MDG- Millennium Development Goals ,MI-Male involvement, MMR-Maternal Mortality Ratio, MRRHIRB- Mbale

Regional Referral Hospital Institutional Review Board, SRH- Sexual and Reproductive Health, SDGSustainable Development Goal

\section{Refeences}

1. Organization, w.H., Men and fertility regulation in:Progress in Human Reproduction Research. WHO,Switzerland, 1994. 47. 
2. Hezner, J.f., Men's involvement in family planning.Reproductive Health matters. 1996. 7: p. 146-154.

3. Fund, U.N.P., Programme of action adopted at the International Confrence on Population and Development,Cairo ,1994,United Nations Poulation Fund, newyork. 1996.

4. International Conference on Population and Development (ICPD), C., Egypt 1994:, Frameworks on Male Involvement in Reproductive Health. 1994.

5. Davis J, L.S., Holmes W., Men and maternal and newborn health: benefits, harms, challenges and potential strategies for engaging men. Melbourne, Australia: Compass: Women's and Children's Health Knowledge Hub. 2012.

6. Organization, W.H., World Health Day ;Safe Motherhood 1998.

7. Ruth Atuhaire, W.K., Factors Contributing to Maternal Mortality in Uganda. African Journal of Economic Review, 2016. 4(2).

8. Dowswell T, C.G., Duley L, Gates S, Gülmezoglu AM, Khan-Neelofur D, Piaggio G., Alternative versus standard packages of antenatal care for low-risk pregnancy. PMC:Cochrane Database Syst Rev, 2015. 7.

9. Singh K, B.S., Haney E, Olorunsaiye C, Brodish P, Gender equality and childbirth in a health facility: Nigeria and MDG5. Afr J Reprod Health, 2012. 16(3): p. 122-128.

10. Organization, W.H., WHO Recommendations on Antenatal Care for a Positive Pregnancy Experience. 2016.

11. Committe, E.S., The Public Health Importance of Antenatal Care. 2015.7 (1): p. 5-6.

12. Yargawa, J., \& Leonardi-Bee, J. , Male involvement and maternal health outcomes: systematic review and meta-analysis. Journal of Epidemiology and Community Health, 2015. 68(6): p. 604-612.

13. Alio AP, S.H., Kornosky JL, Richman AM, Marty PJ: , Feto-infant Health and Survival: Does Paternal Involvement Matter? Matern Child Health J, 2009.

14. Nations, U., Resolution adopted by the General Assembly on 25 September 2015 :Agenda items 15 and 116 Transforming our world: the 2030 Agenda for Sustainable Development. 2015. Seventieth session.

15. Organization., W.H., WHO Statement on Caesarean Section Rates. World Health Organization (2016). . Google Scholar, 2016.

16. Organization, W.H., HEALTH IN 2015: FROM MDGs TO SDGs.

17. UNICEF, Progress for Children. A report card on maternal mortality No.7. United Nations Children's Fund 2008. 2008.

18. Geneva, W.H.O., WHO: Maternal Mortality in 2005. Estimates developed by WHO, UNICEF, UNFPA and the World Bank. 2007.

19. Singh K, B.S., Influence of Women's Empowerment on Maternal Health and Maternal Health Care Utilization: A Regional Look at Africa. [http://paa2011.princeton.edu/papers/110362, 2010. 
20. Lincetto O, M.-A.S., Gomez P, Munjanja S: , Antenatal Care: Chapter 2. In Opportunities for Africa's Newborns. [http://www.who.int/ pmnch/media/publications/aonsectionlll_2, 2006.

21. Justice, S.G., BUILDING MALE INVOLVEMENT IN SRH:A basic model for Male Involvement in Sexual and Reproductive Health and Rights. 2012.

22. Byamugisha, R., Tumwine, J. K., Semiyaga, N., \& Tylleskär, T. , Determinants of male involvement in the prevention of mother-to-child transmission of HIV programme in Eastern Uganda: a crosssectional survey. Reproductive Health, 2010. 7(1).

23. Falnes, E., Moland, K., Tylleskär, T., de Paoli, M., Msuya, S. E., \& Engebretsen, I. M. (2011). \&quot, ;It is her responsibility\&quot;: partner involvement in prevention of mother to child transmission of HIV programmes, northern Tanzania. . Journal of the International AIDS Society, 2011. 14(1).

24. Martin LT, M.M., Milot AS, Halle T, Hair EC, The effects of father involvement during pregnancy on receipt of prenatal care and maternal smoking. Matern Child Health J 2007. 11: p. 595-602.

25. Redshaw, M., \& Henderson, J., Fathers' engagement in pregnancy and childbirth: evidence from a national survey. BMC Pregnancy and Childbirth, 2013. 13(1).

26. Morfaw F, M.L., Thabane L, et al., Male involvement in prevention programs of mother to child transmission of HIV: A systematic review to identify barriers and facilitators. Systematic reviews. http://www.ncbi.nlm.nih.gov/pubmed/23320454. , 2013. 2(1)(5).

27. Raymond Tweheyo, J.K.-L., Nazarius M Tumwesigye, Juliet N Sekandi, Male partner attendance of skilled antenatal care in peri-urban Gulu district, Northern Uganda. BMC Pregnancy and Childbirth, 2010. 10(53).

28. Seruwagi, K.F.K.a.G.K., Determinants of Male Partner Involvement in Antenatal Care in Wakiso District, Uganda British Journal of Medicine \& Medical Research, 2016. 18(7).

29. Joshua Panyin Craymah Robert Kwame Oppong, a.D.A.T., Male Involvement in Maternal Health Care at Anomabo, Central Region, Ghana. International Journal of Reproductive Medicine, 2017.

30. Baiden F, R.P., Baiden R, Williams J, Hodgson A, Boelaert M, Buve A:, voluntary counselling and HIV testing for pregnant women in the Kassena-Nankana district of northern Ghana: is couple counselling the way forward? AIDS Care, 2005. 17: p. 648-657.

31. Byamugisha R, A.A., Ndeezi G, Karamagi CA, Tylleskar T, Tumwine JK:, Male partner antenatal attendance and HIV testing in eastern Uganda: a randomized facility-based intervention trial. J Int AIDS Soc, 2011. 14(1): p. 43.

32. Ditekemena J, M.R., Koole O, Colebunders R, Kashamuka M, Tshefu A, Kilese N, Nanlele D, Ryder R:. „, Male partner voluntary counselling and testing associated with the antenatal services in Kinshasa, Democratic Republic of Congo: a randomized controlled trial. Int J STD AIDS 2011. 22(3): p. 165-170.

33. Bhatta, D.N., Involvement of males in antenatal care, birth preparedness, exclusive breast feeding and immunizations for children in Kathmandu, Nepal. BMC Pregnancy and Childbirth, 2013. 13(14). 
34. Uganda, R.o., National Population and Housing Census 2014 Area Specific Profiles Buyende District. 2017.

35. Lavrakas, P.J., Kish, Leslie (1910-2000) In: Encyclopedia of Survey Research Methods. SAGE Research Methods, 2008.

36. Nyasiro S. Gibore, T.A.L.B.a.S.M.K., Factors influencing men's involvement in antenatal care services: a cross-sectional study in a low resource setting, Central Tanzania. BMC Reproductive Health, 2019. $16(52)$.

37. Maxwell Tii Kumbeni, F.A.Z., John Ndebugri Alem,Sylvia Apana Nborah, Factors Influencing Male Involvement in AntenatalCare in the Kassena Nankana Municipal in the Upper East Region, Ghana. European Scientific Journal, 2019. 15(21).

38. Margaret Duah Atuahene, S.A.-A., Nana Frema Atuahene, Martin Adjuik and John Kuumuori Ganle, Inclusion of men in maternal and safe motherhood services in inner-city communities in Ghana: evidence from a descriptive cross-sectional survey. BMC pregnancy and childhealth, 2017. 17(419).

39. Elizabeth Kabanga, A.C., Namanya Basinda and Domenica Morona, Prevalence of male partners involvement in antenatal care visits - in Kyela district,Mbeya. BMC Pregnancy Childbirth 2019. 19( 321 ).

40. Larissa Jennings, M.N., Megan Cherewick, Michelle Hindin3, Britta Mullany and Saifuddin Ahmed, Women's empowerment and male involvement in antenatal care: analyses of Demographic and Health Surveys (DHS) in selected African countries BMC Pregnancy and Childbirth, 2014. 14(297).

41. Ling, B.B.H.K., Male involvement in maternal healthcare through Community- based Health Planning and Services: the views of the men in rural Ghana. BMC Public Health, 2017. 17(693).

42. Deressa, W.T.W., Barriers to husbands' involvement in maternal health care in Sidama zone, Southern Ethiopia: a qualitative study. BMC Pregnancy Childbirth 2020. 20(21).

43. Peneza, S.O.M.a.A.K., Perceptions on male involvement in pregnancy and childbirth in Masasi District, Tanzania: a qualitative study. bmc Reproductive Health, 2018. 15(68).

44. Bukach, F.K.O.a.a.S.A., Barriers to men's involvement in antenatal and postnatal care in Butula, western Kenya. Afr J Prim Health Care Fam Med, 2019. 11(1)(1911).

45. Neha Pruthi, S.B., Vandana Singh, Knowledge, attitude and practice regarding antenatal care among husbands attending antenatal clinic in a tertiary care hospital. International Journal of Community Medicine and Public Health, 2016. 3(7): p. 1741-1744.

46. Health, T.R.o.U.M.o., Uganda Clinical guidelines 2016. www.health.go.ug, 2016: p. 641.

47. Sally Kura, J.V.a.P.C.-C., Male involvement in sexual and reproductive health in the Mendi district, Southern Highlands province of Papua New Guinea: a descriptive study. BMC Reproductive Health, 2013. 10(46).

48. Nompumelelo Yende, A.V.R., Nora S. West, Jean Bassett,and Sheree R. Schwartz Acceptability and Preferences among Men and Women for Male Involvement in Antenatal Care. Hindawi :Journal of 
Pregnancy, 20172017.

49. Eli Fjeld Falnes, c.a.K.M.M., Thorkild Tylleskär,Marina Manuela de Paoli,Sia E Msuya,and Ingunn MS Engebretsen, "It is her responsibility": partner involvement in prevention of mother to child transmission of HIV programmes, northern Tanzania. J Int AIDS Soc., 2011. 14(21).

50. Kenneth Nesane, S.M.M.a.H.S., Male partners' views of involvement in maternal healthcare services at Makhado Municipality clinics, Limpopo Province, South Africa. Afr J Prim Health Care Fam Med., 2016. 8(2)(929).

51. Fekede Asefa, A.G., Yadeta Dessie, Male partners involvement in maternal ANC care: The view of women attending ANC in Hararipublic health institutions, eastern Ethiopia. Science Journal of Public Health, 2014. 2(3): p. 182-188.

52. Lucy I Kululanga, Johanne Sundby, Address Malata and Ellen Chirwa, Striving to promote male involvement in maternal health care in rural and urban settings in Malawi - a qualitative study. bmc Reproductive Health, 2011. 8(36)

\section{Figures}

\section{Reason for not attending ANC.}

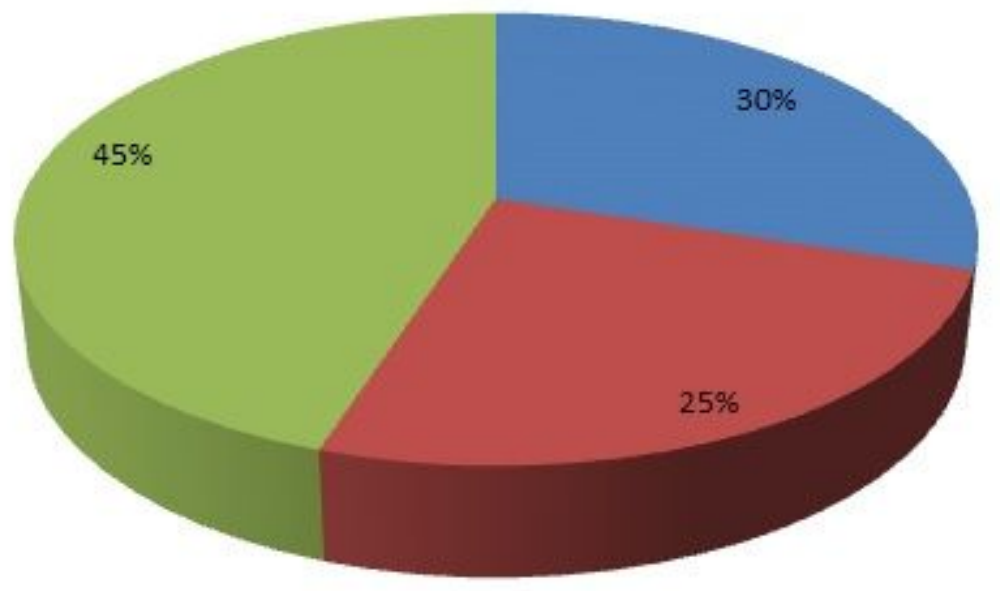

I am busy

I I did not know

wers

\section{Figure 1}

Reasons for males not attending ANC with partner. 


\section{A pie chart showing the number of men that had received a service at ANC.}

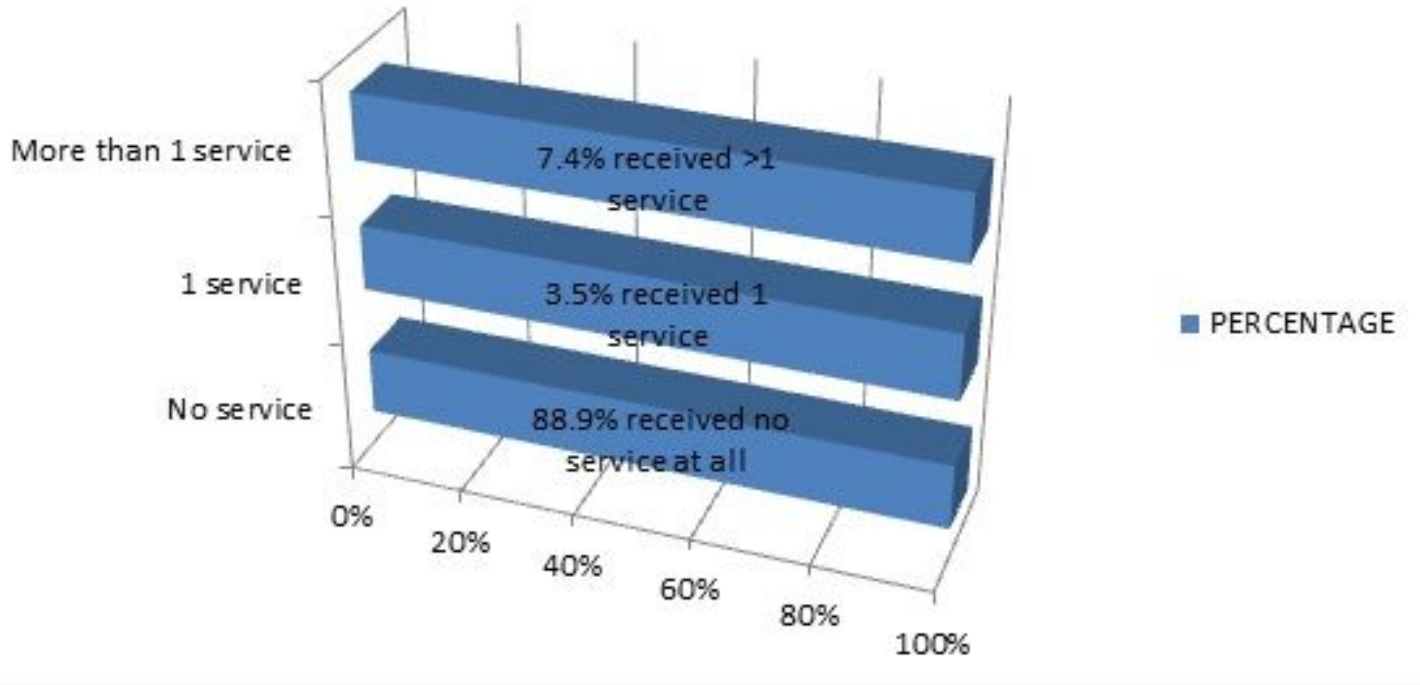

Figure 2

Percentage distribution of men who had ever received a service when they went for ANC with their spouses other than HIV testing.

\section{Supplementary Files}

This is a list of supplementary files associated with this preprint. Click to download.

- kiderasupplement.docx

- KIDERACOREQ.docx 